\title{
Mathematical HOTS Cultivation via Online Learning Environment and 5E Inquiry Model: Cognitive Impact and the Learning Activities
}

\author{
https://doi.org/10.3991/ijet.v14i24.12071 \\ Noraini Ramlee, Mohd Shafie Rosli ( $($ ) \\ Universiti Teknologi Malaysia, Johor Bahru, Malaysia \\ shafieroslidutm.my \\ Nor Shela Saleh \\ Universiti Tun Hussein Onn Malaysia, Johor, Malaysia
}

\begin{abstract}
An ideal education is the one that enhance cognitive ability. In Malaysia, educators are currently putting enormous effort to uplift higher order thinking skills (HOTS) among students at various educational levels. The advancement of technology enables educators to apply online learning environment to further catalyze the effort. Integration of correct pedagogy is essential, $5 \mathrm{E}$ inquiry model by Bybee was implemented to $5 \mathrm{E}$ online learning environment $-\mathrm{a}$ learning environment developed for this research. The purpose of this research is to enhance HOTS among the samples. Thus, the cognitive impact of the learning environment was studied. The current gap of the learning activities that improve HOTS was addressed by probing into the activities done by samples. Samples are thirty-three secondary school students and had treatment with the learning environment for 4 weeks. T-test conducted found that samples' HOTS statistically significant higher after treatment compared to prior to the treatment, $t(32)=-20.95, p<0.05$ that indicates the treatment improve samples' HOTS. The learning activities that materialize HOTS improvement is engaging learning module and HOTS related video. This research proves that human HOTS ability can be nurtured by using technology enhanced learning environment with the appropriate pedagogical approach. Deeper fundamental research regarding the process of learning that nurture HOTS is highly recommended in the future - one of the authors is currently working on.
\end{abstract}

Keywords-Higher order thinking skills, learning activities, online learning environment, 5E model, mathematics education

\section{Introduction}

This paper is focused toward the application of inquiry-based online learning environment in improving HOTS in mathematics. The online learning environment was used in Malaysia. Online learning environment potential in improving and enhancing cognitive ability has been well recognized [1]. It allows for active self-regulated 
learning, exposing students to various impactful online activities that facilitate their cognitive development.

\subsection{Inquiry online learning environment}

The history of online learning environment in Malaysia can be traced back to the implementation ICT and English initiative better known as PPSMI by Ministry of Education in 2003. The Ministry of Education believes by incorporating ICT into the education sector does catalyse the nation toward becoming a high-income nation [2]. It began an era of active online learning environment integration in Malaysia either in school as well as university. Rosli et al. [3] report the positive impact of inquiry online learning environment toward Malaysian students' thinking level in school. As the exposure to online learning taken place, it gives impact toward Malaysian. Tawil et al. [4] reported that university students in Malaysia perceived online learning as important. Embi et al. [5] find that Malaysian lecturers are increasingly using the online learning environment. Students perceive video as an effective blended learning tool while online lecture as significant to them [6].

As Malaysian is focusing toward enhancing thinking skill, in ensuring employability to embrace the industrial revolution 4.0. Inquiry become the centre of attention among the researchers in online learning environment. In Malaysia, [7] had implemented guided inquiry into web-based learning. Later, in 2015 an improved learning web - technology enhanced learning environment with inquiry pedagogical overlay was implemented by [3]. Both researchers reported improvement in samples achievement. Inquiry online learning environment enhances problem solving ability [8]. Therefore, the potential of this technology is enormous in education and should be given significant attention by researchers and educators as well.

\subsection{The need to improve HOTS in Malaysia}

According to TIMSS and PISA, Malaysia need improvement in HOTS. Recent research reported that HOTS in Malaysia still can be improved. Omar et al. [9] and Omar et al. [10] reported the drawback faces by Malaysian secondary school students to attain HOTS in chemistry. The drawbacks are mainly from the aspect of cognitive ability. Raub et al. [11] further reinforce the need to improve HOTS via the medium of cognitive improvement, they reported students faces problem regarding chemical literacy which eventually decreasing the ability toward HOTS.

In science, [12] reported the same problem. HOTS is relatively low among primary school students in mathematics. Earlier, [13] reported that HOTS is low among school students prior to treatment. The latest research by [14] reported the low HOTS faces by students in secondary school but solved by proper empirical treatment. Therefore, no doubt that improving HOTS is an important manoeuvre in the Malaysian education system as emphasized by the Ministry of Education. 


\subsection{Research objectives}

This research is being guided by research objectives that was derived from idea to solve problem stated earlier in this research paper. The research objectives are:

- To investigate the cognitive impact of the 5E online learning environment in enhancing HOTS among samples.

- To probe into the activities that improve HOTS among the samples in the 5E online learning environment.

The following research questions are the main guidelines in solving the stated problem.

- What is the cognitive impact of the 5E online learning environment in enhancing HOTS among samples?

- What are the activities that improve HOTS among samples in the 5E online learning environment?

\section{Methodology}

This research is using pre-experimental research design due to its cost effectiveness and researchers are bound to the permission and agreement from samples. Preexperimental research design gives researcher the ability to produce a generalized outcome to describe the nature of HOTS improvement in Malaysia. The stated research design exposes the result toward threat, the threat was minimized as the samples had learnt the topic before and pretest was done with samples had experience with the content.

The data was analysed using quantitative and qualitative methodological approaches. Quantitative data involves data collected from the Quadratic Equation HOTS Test. The test is conducted twice during the research as pretest and posttest. The online learning environment was developed using Moodle, an open source LMS widely used in the Malaysiaan education ecosystem. To compensate for the probability some sample might not familiar with Moodle, introduction course is conducted prior to the intervention.

\subsection{Treatment with 5E online learning environment}

Samples had learnt the quadratic equation few months before the intervention, through the ordinary traditional classroom approach. After samples, answered the pretest, they are learning quadratic equation using the online learning environment developed using the 5E inquiry model as its constructivism learning model. The $5 \mathrm{E}$ inquiry model is adopted from [15] who have developed the model based on Atkin and Karplus learning cycle. The five phases of learning proposed by Bybee consist of engagement, exploration, explanation, elaboration and evaluation phase. These phases are the heart of developing the online learning environment. Online activities and 
engagement were designed and executed according to the $5 \mathrm{E}$ model of inquiry. External sources that were reported as facilitating the $5 \mathrm{E}$ model and cognitive improvement such as videos and external link were also embedded into the 5E online learning environment. Authors had successfully developed the learning environment; however, it is not included in this research paper. The examples of learning activities derived from $5 \mathrm{E}$ model of inquiry implemented in the learning environment are as in Table 1.

Table 1. Example of the learning activities derived from $5 \mathrm{E}$ in the online learning environment

\begin{tabular}{|l|l|}
\hline \multicolumn{1}{|c|}{ Phase } & \multicolumn{1}{c|}{ Learning Activities } \\
\hline Engagement & $\begin{array}{l}\text { Samples engage the induction prepared by the researcher. Samples had learned the } \\
\text { topic in the traditional classroom approach before the intervention. This phase serves } \\
\text { as a medium to attract samples' attention to the learning process and the learning } \\
\text { environment itself. It also gave ample time for the students to adapt to the student- } \\
\text { centred approach. Learning problem for students to solve was given in this phase. }\end{array}$ \\
\hline Exploration & $\begin{array}{l}\text { Samples were exploring ideas in a collaboration mode via the online learning envi- } \\
\text { ronment. Here, the samples had engaged the ICT facilities prepared in the learning } \\
\text { environment. The teacher acts as an instructor. }\end{array}$ \\
\hline Explanation & $\begin{array}{l}\text { Samples collaborate to solve the problems given during the engagement session. } \\
\text { They were asked to prepare a Microsoft PowerPoint presentation and later presented } \\
\text { in the class and shared via the online learning environment. }\end{array}$ \\
\hline Elaboration & $\begin{array}{l}\text { In this phase, samples were given the opportunity to conceptualize their understand- } \\
\text { ing via critique and elaborate the presentation done by their group and other group. }\end{array}$ \\
\hline Evaluation & Samples answered the posttest \\
\hline
\end{tabular}

Instructional design plays an imperative part in the design and development of an online learning environment, for this research ADDIE is used. The sample ability to use Moodle, computer and the Internet are analysed in the analysis stage. Decision to uses $5 \mathrm{E}$ model is centred on a rigorous literature review done in the design stage. Development of the online learning environment is made by customizing Moodle. Samples engagement with the online learning environment is approximately four weeks, and the whole treatment is about six weeks including the pretest and posttest sessions. It is the implementation and evaluation stage of the ADDIE.

\subsection{Instruments}

Quadratic Equation HOTS Test is the main instrument in this research, it was developed according to the Ministry of Education's syllabus with the main purpose of measuring HOTS performance using non-routine mathematical problems. The HOTS guideline from the ministry is referred to ensure the instrument alignment to HOTS in the context of Malaysia. Three teachers who are experts in HOTS and mathematics as well are sampled to validate the instrument. These experts had undergone extensive training in HOTS. The Quadratic Equation HOTS Test is a test that involves manual calculation answered in physical paper format form. It was later integrated into the learning environment, enabling samples to answer the pretest and posttest online. The instrument is reliable with Cronbach's alpha value of 0.73 by 20 samples from four different schools using the internal consistency technique. A pilot study with 20 sam- 
ples, is suitable with sample size proposed by [16]. Samples taking part in the pilot study are not included in treatment using the online learning environment.

In order to gain further insight into the HOTS improvement, qualitative data were included. Qualitative data are collected using Moodle log facility, an analytic tool available in Moodle. The samples' log in the learning environment is recorded using this facility. Three selected sample data are further analysed to understand how HOTS improvement transpire consisting of the sample with the highest, moderate and lowest improvement. The data logging is conducted throughout the intervention session.

\subsection{Method of analysis}

Researcher marked sample answer from the Quadratic Equation HOTS Test based on prescribed scheme. Score later transformed into SPSS format using SPSS version 24. Descriptive analysis of the mean and standard deviation was reported, data was then analysed using paired sample t-test.

The log data is stored online in the Moodle. The data is downloaded in Excel format once the theoretical saturation is shown and later transcribed into illustrated form using the lag sequential analysis technique. The samples are considered as achieving saturation when they are showing the repeated pattern of interaction with the online learning environment. Lag sequential analysis is a popular technique in studying online learning processess as did by [17]. The transcription process involves thousands of raw data. Through a screening process, only expressive data are reported. Each activity is coded as shown in Table 2.

Table 2. Activity codes for sequential analysis technique

\begin{tabular}{|c|l|}
\hline Code & \multicolumn{1}{|c|}{ Activity } \\
\hline $\mathrm{a}$ & view and engage main course page \\
\hline $\mathrm{b}$ & view and engage embedded learning video \\
\hline $\mathrm{c}$ & engage learning module \\
\hline $\mathrm{d}$ & view and engage evaluation module \\
\hline
\end{tabular}

\subsection{Sampling}

This research has thirty-three samples from a secondary school from a district in Malaysia. Selection of school is based on simple random sampling technique. All samples take part in the pretest, intervention using the inquiry online learning environment and the posttest. Only three samples with the highest, moderate and lowest improvement are sampled for the data log. Analysing all samples is not time efficient and expose researcher to the probability of repeated activities because of saturation. 


\section{$3 \quad$ Result and Finding}

The result and finding are structured according to the stated research objectives. The first research objective was discussed using quantitative methodological approach. The second objective involves qualitative data interpretation.

\subsection{Cognitive impact of $5 \mathrm{E}$ online learning environment toward HOTS}

A normality test using the Shapiro-Wilk was conducted to determine the suitability of the data set to be tested parametrically. The output of the normality test and Q-Q plot was examined. The hypotheses used are H0: data normal distribution and H1: data not normally distributed with the degree of confidence $=0.95, \alpha=0.05$. The $\mathrm{p}$ value for pretest is 0.97 , resulting in the acceptance of $\mathrm{H} 0$ - data set is normally distributed. The p-value for posttest is 0.28 , again the p-value $>\alpha$ and $\mathrm{H} 0$ is accepted. Confirmation using Q-Q plot shows the data points are close to the diagonal line. As both data sets are normally distributed, they are eligible for parametric test using dependent t-test.

To measure the effectiveness of the developed $5 \mathrm{E}$ online learning environment, a set of pretest and posttest are conducted in between the treatment using the learning environment. These tests give insight into the HOTS level of the samples before and after the treatment. Analysis of the pretest and posttest is as in Table 3.

Table 3. Pretest and posttest data analysis output

\begin{tabular}{|l|c|c|c|c|}
\hline \multicolumn{1}{|c|}{ Test } & Mean & SD & Minimum & Maximum \\
\hline Pretest & 38.86 & 9.03 & 21.05 & 58.77 \\
\hline Posttest & 76.87 & 6.87 & 64.04 & 90.45 \\
\hline
\end{tabular}

As illustrated in Table 3, samples show low HOTS achievement with mean only 38.86 with a standard deviation value of 9.03 . The wide standard deviation shows that the samples are heterogenous in their HOTS level. The wide gap between the minimum (21.05) and the maximum (58.77) score reinforces the fact of sample wideranging disparity.

Comparison between the pretest and posttest shows a visible improvement in HOTS. Samples exhibit greater HOTS achievement with mean increased to 76.87 . Better result of a minimum score of 64.04 and maximum score achieved 90.45. The standard deviation value has shrunk to 6.87 .

Despite the shown improvement, the value is not proven statistically. Thus, t-test was conducted to verify the significant of the improvement. The t-test result is as in Table 4.

Table 4. T-test result of the pre-test and post-test

\begin{tabular}{|c|c|c|c|c|c|}
\hline & Mean & SD & df & t & Significant \\
\hline Pretest - Posttest & -38.01 & 10.42 & 32 & -20.95 & .000 \\
\hline
\end{tabular}


As shown in Table 4, it is a significant difference between the pretest and the posttest conducted in this research. As noted earlier, the mean score is higher in the postest compared to the pretest. Analysing the data set and statistical test done, it infers that sample's HOTS level increase tremendously after using the 5E online learning environment. Exposing that using the 5E model, an inquiry-based approach integrated into technological advanced online learning environment able to enhance human HOTS thinking level and perhaps other cognitive skills as well.

\subsection{The learning activities}

Previous research suggests online learning environment improves human abilities from various spectrum, such as cognitive and affective. Despite the success of developing such technology, the activities performed during the learning process that eventually lead to the cognitive improvement are not yet being discussed thoroughly. The gap needs to be filled with suitable data. Moodle provides cognitive researchers with learning analytic tools that can be manipulated to understand this might be unique process.

In this research, the learning activities are logged using Moodle Log. Three samples as stated in the methodology was analysed, theoretical saturation had taken place before the researcher ended the treatment. Details on improvement of the samples are as in Table 5.

Table 5. Samples improvement data

\begin{tabular}{|c|c|c|c|l|}
\hline Sample & Pretest & Posttest & Difference & \multicolumn{1}{|c|}{ Label } \\
\hline A & 28.07 & 82.46 & 54.39 & Highest improvement \\
\hline B & 47.37 & 90.35 & 42.98 & Moderate improvement \\
\hline C & 58.77 & 83.33 & 24.56 & Lowest improvement \\
\hline
\end{tabular}

The learning activities logged from the sample with the highest improvement is as in Figure 1.

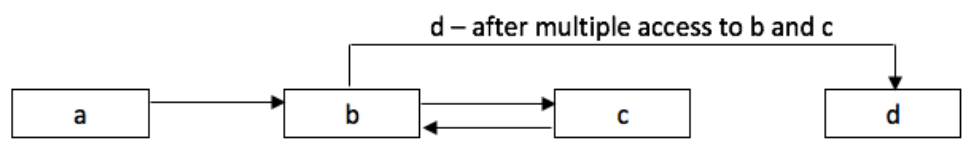

Fig. 1. Learning activities of the sample with the highest improvement, sample A

Sample A accessed the embedded learning video, b before the learning module, $\mathrm{c}$. Sample spent most of his or her time in the online learning environment engaging $b$ and $\mathrm{c}$ alternately. After much of the interaction with $\mathrm{b}$ and $\mathrm{c}$, sample proceeded to the evaluation module coded as $\mathrm{d}$. The learning activities logged from the sample with the moderate improvement identified as Sample B are in Figure 2. 


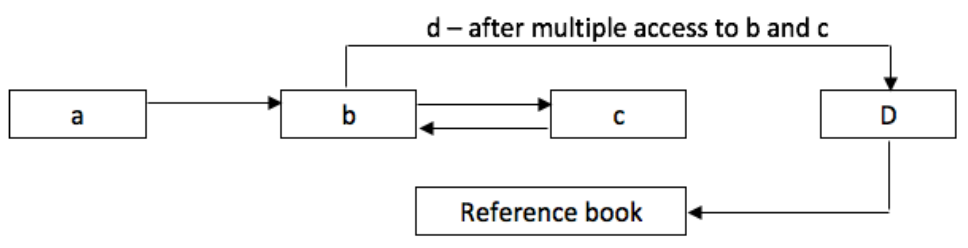

Fig. 2. Learning activities of the sample with the moderate improvement, sample B

Almost the same pattern of activities logged from sample B. As plotted from sample A, b and c are the most acted behaviours for this sample. Sample B refers to reference book, which is an external source out of the $5 \mathrm{E}$ online learning environment. This rather exclusive behaviour is not giving superior influence on HOTS as in fact sample B is inferior to sample A in improvement, but remarkably scored higher than sample A in the posttest. Sample with the lowest improvement, sample C learning activities is illustrated by Figure 3 .

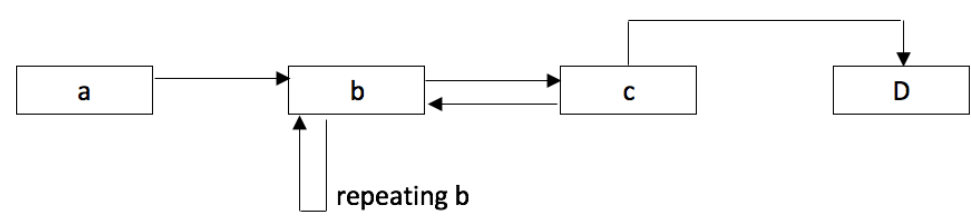

Fig. 3. Learning activities of the sample with the moderate improvement, sample C

Sample C showing deviation from sample A and B. High frequency of repeating $b$ before navigating to $\mathrm{c}$ and eventually answer the evaluation at $\mathrm{d}$. Unlike sample A and $B$ who navigate to $d$ from $b$, sample $C$ navigates to $d$ from $c$ instead of $b$.

\section{Discussion}

As the education evolves, HOTS is now an important missing puzzle in the system. Students with HOTS is now the centre of focus among educators in Malaysia for the past few years. Authors had strategized a mechanism to enhance HOTS among secondary school students in mathematics. As stated earlier, the main objective of this research is to enhance HOTS among the samples. This experimental research study the effectiveness of 5E online learning environment in enhancing HOTS among mathematics secondary school students in Malaysia. The online learning environment is developed using Moodle and the learning activities were designed according to $5 \mathrm{E}$ inquiry model by [15]. The samples engaged the learning environment for around one month. They are exposed to learning via online medium, online assessment and information search. Their learning activities were logged by the online learning environment.

The first research objective states: to measure the cognitive impact of the 5E online learning environment in improving HOTS. Result from Quadratic Equation HOTS 
Test administrated as pretest and posttest give intuition into the cognitive impact of the developed learning environment. The result of t-test conducted clarified that treatment using 5E online learning environment for four weeks escalate samples' HOTS achievement.

HOTS require a scientific approach and a systematic thinking process. While students and schools inclined toward rote learning and memorization, research found that HOTS among Malaysian students are still not achieving its expected mark. Impotent to materialize thinking process might lead to low HOTS. Students need engagement with the appropriate learning process, in this case inquiry-based was found as suitable. This impactful engagement indirectly trains mind to think in a systematic way and enable derivation of argument in accordance to science and logic. Yet, implementation of such scientific oriented approach is not new. Umar and Maswan [7] implemented guided inquiry approach to 141 Malaysian secondary school students, found that inquiry has the potential to be an effective instruction. As low HOTS is persistent, advancement in online technology renders online learning environment as possible. As its growth, online learning bridges the gap between effective pedagogy, learning and cognitive nurturation. Online platform of learning is worth considered as an inventive learning tool for the new century.

Online learning environment further augments the ability to nurture learning and cognitive skills. It is in line with [18] that suggest online learning able to pave for better higher order cognition. It does not deny the need for face-to-face learning as [19] suggest that the combination of traditional, online and team-based learning developed HOTS among their samples.

There are arguments regarding the minimum duration needed for an experiment to impact the cognitive ability of samples. Over four-weeks is suitable for school classed as semi-rural as did by [20]. Twenty-five hours engagement within 10 weeks of treatment give positive impact on samples problem solving ability among Taiwanese university software engineering students [21]. For this research, treatment was done for four-weeks and cognitive improvement in form of HOTS were recorded. A minimum of four-weeks treatment is adequate to enhance thinking ability [3].

The second research objective states: to probe into the activities that improve HOTS in the 5E online learning environment. The whole samples were logged in the learning environment. Three selected samples show exceptional activities that gave researchers insight into the activities. Sample A had a substantially higher engagement and hits with the learning environment compared to Sample B and C. Engaging module and video are the main activities done with the highest frequency. Sample A access the two parts of the learning environment repeatedly before proceeding to evaluation part. Activities with the module and video are longer in module and video than evaluation. Disproportion from 5E model suggested by Bybee et. Al (2006) is noticeable here. It does not seem to jeopardize learning, as the frequency of engaging module and video is proportional to HOTS achievement. Sample B and C with lower frequency showed lower improvement. Researchers assume that higher frequency of the engagement opens toward better cognitive training of thinking systematically and scientifically. It explains the difference in HOTS achievement between the samples. The traditional reference book seems ineffective in improving HOTS, but facilitate 
sample to attain higher HOTS as did by Sample B. As book is not designed primarily to nurture HOTS it might increase conceptual knowledge but not cognitive ability. Yet, conceptual understanding has been the foundation to improve HOTS. Without extensive activities with module, in which have almost the same function as book - to gain conceptual knowledge sample $\mathrm{C}$ gain lowest in HOTS improvement. Despite the fact that each sample is receiving the same form of intervention, they are show different patterns of interaction. The cognitive skill of the samples may explain the differences. Sample with good cognitive skill, interact systematically using approach in line with learning theory in education. Sample without a robust cognitive skill faces confusion in the online learning environment, renders a simpler interaction or decides for offline learning. This notion is supported by previous studies reporting that interaction is related to the cognitive of the sample [22].

\section{Conclusion}

Cultivating HOTS among students is a crucial effort in enriching learning. Authors found that the fact that HOTS is relatively weak among students as described in the finding of the pretest. Nevertheless, it is possible to improve HOTS among Malaysian students. Through active engagement with the technology such as online learning environment and suitable pedagogical instruction, it promotes HOTS cultivation among samples. Thus, current efforts by the Malaysia Ministry of Education is in fact on its right track with significant introduction of educational technologies are currently in its progress. Teachers undergo training to handle such technologies and the ministry open a wide opportunity for graduated teachers to pursue for postgraduate are among the others that actually in trend with the global development. Learning activities are recommended to focusing toward cognitive training, as it is the essence of HOTS improvement.

\section{Acknowledgement}

Authors would like to thank Ministry of Education and Universiti Teknologi Malaysia for the research funding through Fundamental Research Grant Scheme (FRGS) with Project Number R.J130000.7831.4F952.

Article processing charge was provided by UTHM Research Fund (E15501).

\section{$7 \quad$ References}

[1] Jesionkowska, J. (2018). Designing online environment for collaborative learning in a scientific community of practice. In: Auer M., Tsiatsos T. (eds) The challenges of the digital transformation in education. ICL 2018. Advances in Intelligent Systems and Computing, vol 916. Springer, Cham

[2] Ministry of Education (2012). Education Development Blueprint 2013 -2025. Kuala Lumpur: Ministry of Education. 
[3] Rosli, M.S., Aris, B., and Ahmad, M.H. (2015). Online intellectual transformation system. Contemporary Engineering Sciences, 8 (1-4), 39 - 47. https://doi.org/10.12988/ces.2015.4 12254

[4] Tawil, N.M., Zaharim, A., Shaari, I., Ismail, N.A., and Embi, M.A. (2012). The acceptance of e-learning in engineering mathematics in enhancing engineering education. Journal of Engineering and Applied Sciences, 7 (3): 279 - 284. https://doi.org/10.3923/jeasci.2012.27 $\underline{9.284}$

[5] Embi, M.A., Hamat, A., and Sulaiman, A. H. (2012). The use of learning management systems among Malaysian university lecturers. International Journal of Learning, 18 (4): 61 70. https://doi.org/10.18848/1447-9494/cgp/v18i04/47554

[6] Wai, C.C. and Seng, E.L.K. (2015). Measuring the effectiveness of blended learning environment: A case study in Malaysia. Education and Information Technologies, 20 (3), 429 443. https://doi.org/10.1007/s10639-013-9293-5

[7] Umar, I.N. and Maswan, S. (2007). The effect of a web based guided inquiry approach on students' achievement. Journal of Computers, 2(5), 38-43. https://doi.org/10.4304/jep.2.5.3 $\underline{8-43}$

[8] Chanprasitchai, O. and Khlaisang, J. (2016). Inquiry-based learning for a virtual learning community to enhance problem-solving ability of applied Thai traditional medicine students. The Turkish Online Journal of Educational Technology, 15 (4), 77 - 87.

[9] Omar, S.Z., Arshad, M., Rosli, M.S. and Shukor, N.A. (2017a). Chemistry modelling skills: students' understanding on chemical representations at the microscopic level. Advanced Science Letters, 23 (9), 8127 - 8130. https://doi.org/10.1166/asl.2017.9847

[10] Omar, S.Z., Arshad, M., Rosli, M.S. and Shukor, N.A. (2017b). Chemical modelling skills: students' understanding on transferring simple molecule to model drawing. Advanced Science Letters, 23 (9), 8259 - 8263. https://doi.org/10.1166/asl.2017.9873

[11] Raub, L.A, Arshad, M.Y., Rosli, M.S. and Shukor, N.A. (2017). Investigating chemical literacy achievement among high-achiever students in Malaysia. Advanced Science Letters, 23 (9), 8425 - 8427. https://doi.org/10.1166/asl.2017.9903

[12] Kassim, E.N., Rosli, M.S. and Atan, A.S. (2018). Implementing science process skill using augmented reality. Proceeding of 2nd International Conference on Science, Technology, Engineering and Mathematics. Kuala Lumpur.

[13] Mat Zin, A.F. (2016). Mathematical HOTS learning environment (unpublished master thesis). Universiti Teknologi Malaysia, Johor Bahru Malaysia. https://doi.org/10.20319/pijss. $\underline{2018.33 .14321441}$

[14] Mustapha, S. (2018). Online mathematical learning environment for statistics based on Polya's model (unpublished master thesis). Universiti Teknologi Malaysia, Johor Bahru Malaysia. https://doi.org/10.20319/pijss.2018.33.14321441

[15] Bybee, R.W., Taylor, J.A., Gadner, A., Scotter, P.V., Powell, J.C.,Westbrook, A. and Landes, N. (2006). The BSCS 5E Instructional Model: Origins, Effectiveness and Applications. Colorado: BSCS

[16] Hertzog, M. A. (2008). Considerations in determining sample size for pilot studies. Research in Nursing \& Health, 31 (2), 180-191. https://doi.org/10.1002/nur.20247

[17] Lamsa, J., Hamalainen, R., Koskinen, P., Viiri, J. and Mannonen, J. (2020). The potential of temporal analysis: combining log data and lag sequential analysis to investigate temporal differences between scaffolded and non-scaffolded group inquiry-based learning processes. Computer \& Education, 143 (2020), 103674. https://doi.org/10.1016/j.compedu.20 19.103674

[18] Troussas, C., Krouska, A., Virvou, M. and Sougela, E. (2019). Using hierarchical modelling of thinking skills to lead students to higher order cognition and enhance social e- 
learning. 9th International Conference on Information, Intelligence, Systems and Applications (IISA), Zakynthos, Greece, 2018, 1-5. https://doi.org/10.1109/iisa.2018.8633669

[19] Othman, S.Z., Zaid, N.M., Harun, J., and Abdullah, Z. (2019). Developing Higher Order Thinking Skill with the 120-minute instructional station rotation (MRSP12) approach: students' perceptions. 2019 IEEE International Conference on Teaching, Assessment, and Learning for Engineering (TALE), Wollongong, NSW, 2018, 1039-1043. https://doi.org/ $10.1109 /$ tale.2018.8615170

[20] Fallon, G. (2019). Using simulations to teach young students science concepts: an experiential learning theoretical analysis. Computers \& Education, 135 (July 2019), 138 - 159. https://doi.org/10.1016/j.compedu.2019.03.001

[21] Lin, Y-T. (2019). Impact of a flipped classroom with a smart learning diagnosis system on students' learning performance, perception, and problem-solving ability in a software engineering course. Computers in Human Behavior. 95 (June 2019), 187-196. https://doi.org/ 10.1016/j.chb.2018.11.036

[22] Zumbach, J., Rammerstorfer, L. and Deibl, I. (2020). Cognitive and metacognitive support in learning with a serious game about demographic change. Computers in Human Behavior, 103 (2020), 120-129. https://doi.org/10.1016/j.chb.2019.09.026

\section{Authors}

Noraini Ramlee is working as a teacher and an expert in mathematics education. She had wide experience of practice at school and active in HOTS related activities.

Mohd Shafie Rosli is a Malaysian active researcher in HOTS and online learning environment with more than a decade of research experience in technological assisted cognitive augmentation. He had supervised a significant number of postgraduate researches on the application of online learning environment in the field of education.

Nor Shela Saleh is serving Universiti Tun Hussein Onn Malaysia. She is an expert in social sciences statistics and research methodology, contributing to data analysis and literature support.

Article submitted 2019-09-15. Resubmitted 2019-11-03. Final acceptance 2019-11-05. Final version published as submitted by the authors. 